\title{
Network Neutrality: A Research Guide
}

\author{
Dr Christopher T. Marsden LL.B., LL.M. \\ University of Essex School of Law
}

\begin{abstract}
First draft for "7th Conference on Internet, Law \& Politics (IDP 2011): Net Neutrality and other challenges for the future of the Internet", at Universitat Oberta de Catalunya School of Law (Barcelona, Spain), to be published in Brown, I. [ed](2012) Handbook of Internet Research, Edward Elgar at www.eelgar.com
\end{abstract}

\section{Net neutrality is not only about economics}

This chapter focuses on the global policy challenge of network neutrality: will governments be able to ensure increasing access to an ever faster Internet while supporting user and content provider expectations that censorship and filtering of their content is kept to a democratically and economically necessary minimum? Or will open Internet access be relegated to a comparatively slow lane, with fast lanes reserved for ISPs' affiliated video, telephony and other preferred services? Communications regulation of telephony, broadcast and the Internet (including consumer electronic commerce) depends on the solutions found to these questions, grouped in the sloganised principle of 'network neutrality'.

Forms of private censorship by intermediaries have been increasing throughout the last decade even as the law continues to declare those intermediaries (mainly ISPs, but increasingly also video hosting companies such as YouTube, social networks such as Facebook, and search providers such as Google) to be 'Three Wise Monkeys'. These intermediaries are not subject to liability for their customers' content under the Electronic Commerce Directive (EC/2000/31) so long as they have no actual or constructive knowledge of that content: if they 'hear no evil, see no evil and speak no evil' (Marsden, 2010a, pp. 105-149). Any net neutrality solution needs to be holistic, considering ISPs' roles in the round. ISPs are a heterogeneous category, ranging from very large network owners such as (UK examples) British Telecom, Vodafone and Virgin Media (owner of the cable TV/telecoms infrastructure), to large retailers such as TalkTalk and Sky, to hundreds if not thousands of much smaller niche business and consumer operators. Current ISP (and government) practices have been highly deceptive in places, blocking content for specific anti-competitive and non-specific traffic management purposes (Donahue, 2010).

Content providers - newspapers, TV companies, search and e-commerce providers and those making usergenerated content - formerly paid a flat rate to access the Internet based on the same service. Those most able and willing to pay may in future receive first-class service, while other content travels in the slow lane. That means that 'medium law' (i.e. mass market content online that formerly used several media) is intimately tied into telecoms law (Marsden et al 2006). Furthermore, security and antiterrorist measures are also driving ISPs towards filtering all incoming traffic. This may change the entire architecture of the Internet, its business model and freedom of speech. It is happening beyond the analysis of the discrete fields of information security, e-commerce law, media law and telecoms law. There are at least two other critical factors at play: concern over illegal and inappropriate content (such as child pornography, music protected by copyright and latterly video files being inappropriately shared, and malware including spam); and the security agenda, which aims to enforce QoS to separate 'good' or preferred from 'bad' or discriminated-against packets. There is a legitimate concern that this represents a division between the rich and powerful senders of packets and the lesser content types. These three policy areas - telecoms, content and security regulation - are coming together. Policies made in their respective arenas are tending to the same result in terms of incentives to deploy network architectures which could change the Internet forever, to become faster and safer but more closed. Competition analysis of bottlenecks was inadequate to address Internet regulation a decade ago. That is not to say that much good work is not being done in economic analysis of networks (Economides 2007), but net neutrality is not simply an economic issue.

\section{Origins of the Controversy: Trust-to-Trust and Control of the Internet}

Network neutrality is the latest phase of an eternal argument over control of communications media. The Internet was held out by early legal and technical analysts to be special, due to its decentred construction, separating it from earlier 'technologies of freedom' (de Sola Pool 1983) including radio and the telegraph. 
Spar (2001) argues that control is a historical evolutionary step in communications media development, while Wu (2010) following Lessig (1999) argues that closure need not be an inevitable outcome.

The Internet had never been subject to regulation beyond that needed for interoperability and competition, building on the Computer I and II inquiries by the Federal Communications Commission (FCC) in the United States (Werbach 2005), and the design principle of End-to-End (E2E) that was first described by Saltzer, Reed and Clark (1984). That principle itself was bypassed by the need for greater trust and reliability in the emerging broadband network by the late 1990s, particularly as spam email led to viruses, botnets and other risks. As a result, E2E has gradually given way to trust-to-trust mechanisms, in which it is receipt of the message by one party's trusted agent which replaces the receipt by final receiver (Clark/Blumenthal 2011). This agent is almost always the Internet Service Provider (ISP), and it is regulation of this party which is at stake in net neutrality.

The development of trust-to-trust has significant implications for network neutrality. Not only are ISPs removing spam and other hazardous materials before they reach the (largely technically uneducated) subscriber, ISPs also can remove other potentially illegal materials on behalf of governments and copyright holders, to name the two most active censors on the Internet, as well as prioritising packets for their own benefit. As a result, the E2E principle would be threatened were it not already moribund. Nevertheless, it is treated by some scholars with an 'almost Talmudic reverence' (Clark/Blumenthal 2011) despite the nature of Internet design documents as 'rough consensus and running code' (RFC rather than Commandments, and solutions to maintain a 1980s style network neutrality are still proposed. Thus initial treatment of network neutrality discussed ensuring four 'Net Freedoms' (FCC 2005) for end-users: freedom to attach devices, run applications, receive the content packets of their choice and to receive 'Service Plan Information...meaningful information' (on which see the section on transparency). Even in 2011, scholars are suggesting freedom to innovate can be squared with design prohibitions (van Schewick 2010), despite over a decade of multi-billion dollar protocol development by the ISP community resulting in the ability to control traffic coming onto their networks (Waclawsky 2005), and wholescale rationing of end-user traffic (see Usage Based Billing Section 6.1).

The lack of trust on the Internet, combined with a lack of innovation in the Quality of Service (QoS) offered in the core network over the entire commercial period of the Internet since NSFNet was privatized in 1991-95 (Harris and Gerich 1996, Crowcroft 2011), has meant that development has focussed almost entirely in the application layer, with Peer-to-Peer programmes such as low-grade Voice over Internet protocol (VoIP) and file-sharing as well as the World Wide Web (WWW) designed during this period. However, 'carrier-grade' voice, data and video transmission was restricted to commercial Virtual Private Networks (VPNs) that could guarantee trust, with premium content attempting to replicate the same using Content Delivery Networks (CDNs) such as Akamai, or the ISPs' own local loop offerings deployed within the user's own network. Berners Lee (2006) explained:

"Net neutrality is this: If I pay to connect to the Net with a certain quality of service, and you pay to connect with that or greater quality of service, then we can communicate at that level. That's all. Its up to the ISPs to make sure they interoperate so that that happens. Net Neutrality is NOT asking for the internet for free. Net Neutrality is NOT saying that one shouldn't pay more money for high quality of service. We always have, and we always will. There have been suggestions that we don't need legislation because we haven't had it. These are nonsense, because in fact we have had net neutrality in the past - it is only recently that real explicit threats have occurred."

Berners Lee was particularly adamant that he does not wish to see the prohibition of QoS because that is precisely the claim made by some US net neutrality advocates - and opposed by virtually the entire network engineering community (QoS is the Holy Grail of Internet architecture).

The legal policy and regulatory implications of rapidly standardising innovation on the communications ecology was well understood by Benkler, who was concerned with the need to maintain interoperability and openness to ensure a 'commons' in which unaffiliated and non-commercial innovation could flourish (Benkler, 1998a, 1998b, building on De Sola Pool, 1983). Network neutrality cannot simply be solved by economic analysis of bottlenecks in transport-based industry, or a convergence of regulation between television and the Internet, but as the delivery mechanism for the global Information Society. The Internet's core values of openness and democracy have been established by accident as well as design. Noam (2008) states: 'There is nothing especially new about [media law's] recent round- net-neutrality - as a conceptual 
issue, or in terms of its policy options, except for the terminology'. In terms of the Internet's engineering, Clark and Blumenthal (2011) argue that the end-to-end argument evolved into a trust-to-trust argument, and that legal and regulatory interpretations need to follow suit. In turn, lawyers such as Benkler (1998) and Lemley and McGowan (1998) have argued that though network effects may tend to closure of the network, regulatory scrutiny may not be the only outcome that will result in greater openness.

It is not novel to claim that protocols regulate user behaviour on the Internet ('Code is law', as Lessig, 1999a, put it), but legal commitment to freedom of speech means that law can regulate the Internet, by enforcing conditions to enable free speech. As Wu (2003a) explains, laws can regulate the Internet as surely as vice versa, and with more constitutional authority if less technical virtuosity (Mayer-Schonberger, 2008; Reidenberg, 2005). By 1998, the innovation-control argument hinged on Microsoft's leveraging of its operating system monopoly into browser and video software, and by 2000 this had led to scrutiny of AOL-Time Warner, notably the potential for foreclosure of Instant Messaging and video (Faulhaber 2001), and of cable-telephony horizontal merger such as that between AT\&T and MediaOne (Lemley and Lessig 1999). This moved on to control over WiFi, an unlicensed spectrum technology capable of providing Local Area Network connectivity and opening the control over end-users exerted by fixed and wireless ISPs (Croxford and Marsden 2001). Net neutrality as a description was first applied to the debate about Internet traffic management practices (ITMP), or Quality of Service on the Internet in 2003 by Columbia University Professor Tim Wu (Lessig and Wu, 2003; Wu, 2003b), though the debate began when academics feared that cable TV's closed business model would overtake the open Internet in 1999 (Lemley and Lessig, 1999; Lessig 1999a, 1999b).

\section{Definition}

'Net neutrality' is a deceptively simple phrase hiding a multitude of meanings.

Net neutrality may be seen to comprise two separate non-discrimination commitments (Marsden 2010a), one of universal service and another of common carriage. Backward-looking 'net neutrality lite' claims that Internet users should not be disadvantaged due to opaque and invidious practices by their current Internet Service Provider - the company providing the Internet connection into their home. The argument here is that a minimum level of service should be provided which offers open Internet access without blocking or degrading of specific applications or protocols - what has been described as an updated form of universal service, generally proposed at $2 \mathrm{Mbps}$. That provides a basic level of service which all subscribers should eventually receive (Mueller 1998).

Forward-looking 'positive net neutrality' describes a practice whereby higher Quality of Service (QoS) for higher prices should be offered on fair reasonable and non-discriminatory (FRAND) terms to all-comers, a modern equivalent of common carriage (Noam, 1994). It is a more debatable principle, with many content providers and carriers preferring exclusive arrangements. The type of service which may be entitled to FRAND treatment could result in short-term exclusivity in itself, as for instance wireless/mobile cell towers may only be able to carry a single high-definition video stream at any one point in time and therefore a monopoly may result. As common carriage dictates terms but not the specific market conditions, transparency and non-discrimination would not automatically result in a plurality of services. I argue against social or economic justifications for either barring any proprietary high-speed traffic at all, or for strict versions of net neutrality that would not allow any traffic prioritisation. There is too much at stake either to expect government to supplant the market in providing higher speed connections, or for the market to continue to deliver openness without the most basic of policy and regulatory backstops to ensure some growth (Meisel, 2010: 20).

The net neutrality problem is complex and far-reaching: attempts to dismiss it as a problem that can be overcome by local loop (last mile) telecoms competition (Cave et al., 2009; Renda, 2008) fail to acknowledge persistent problems with market failure. The physical delivery of Internet to consumers is subject to a wide range of bottlenecks, not simply in the 'last mile' to the end-user. There is little 'middle mile' (backhaul) competition in fixed ISP markets, even in Europe where the commitment to regulation for competition remains, as wholesale backhaul is provided by the incumbent privatised national telecoms provider (in the UK, British Telecom). Even if platforms did compete in, for instance, heavily cabled countries, there would remain ' $n$-sided' market problems in that there is no necessary direct (even noncontractual) relationship between innovative application providers and ISPs (Economides and Tåg, 2007), so that platforms may set rules to 'tax' data packets that ultimately impoverish the open innovation 
value chain, so ultimately causing consumer harm. Thus the archetypal garage start-ups such as Facebook (founded 2003) and YouTube (founded 2005) would have had less opportunity to spread 'virally' across the Internet, as their services would be subject to these extra costs. Many commercial content providers, such as Google, use content delivery networks and other caching mechanisms to accelerate the speed of delivery to users, in essence reducing the number of those 'hops'. Content is therefore already delivered at different speeds depending on the paid priority the content provider assigns to it, but not the ISPs' policies.

\section{How is traffic management changing common carriage?}

Network congestion and lack of bandwidth at peak times is a feature of the Internet. It has always existed. That is why video over the Internet was until the late 1990s simply unfeasible. It is why Voice over the Internet has patchy quality, and why engineers have been trying to create higher QoS. 'End to end' is a twoedged sword, with advantages of openness and a dumb network, and disadvantages of congestion, jitter and ultimately a slowing rate of progress for high-end applications such as High Definition video. E2E may have its disadvantages for those introducing zoning as compared with QoS, and in this it has obvious parallels with 'common carriage'. Common carriers who claim on the one hand the benefits of rights of way and other privileges, yet on the other claim traffic management for profit rather than network integrity, are trying to both have their cake and eat it (Frieden 2010). It is worth stating what common carriage is not. It is not a flat rate for all packets. It is also not necessarily a flat rate for all packets of a certain size. It is, however, a mediaeval non-discrimination bargain between Sovereign and transport network or facility, in which an exchange is made: for the privileges of classification as a common carrier, those private actors will be granted the rights and benefits that an ordinary private carrier would not. As Cherry (2006) has written, common carriers are not a solution to a competition problem, they far predate competition law. They prevent discrimination between the same traffic type - if I offer you transport of your High Definition video stream of a certain protocol, then the next customer could demand the same subject to capacity, were the Internet to be subject to common carriage.

New technology lets any of the ISP routers (if so equipped) look inside a data packet to 'see' its content, via what is known as Deep Packet Inspection (DPI). In the past routers were not powerful enough to conduct more than a shallow inspection that simply established the header information - the equivalent of the postal address for the packet. An ISP can use DPI to determine whether a data packet values high-speed transport - as a television stream does in requiring a dedicated broadcast channel -and offer higher-speed dedicated capacity to that content, typically real-time dependent content such as television, movies or telephone calls using VOIP. Most voice calls and video today use a dedicated line, your copper telephone line or cable line: tomorrow they may use dedicated high-speed lanes on your Internet connection. That could make a good business for ISPs that wish to offer higher capability via DPI (not all ISPs will do so, and it is quite possible to manage traffic less obtrusively by using the DiffServ protocol to prioritise traffic streams within the same Internet channel). As Waclawsky (2005) stated, 'This is the emerging, consensus view: [it] will let broadband industry vendors and operators put a control layer and a cash register over the Internet and creatively charge for it'.

DPI and other techniques that let ISPs prioritise content also allow them to slow down other content, as well as speed up content for those that pay (and for emergency communications and other 'good' packets). This potentially threatens the business of companies that compete with that content: Skype offers VOIP using normal Internet speeds; uTorrent and BBC's iPlayer offer video using peer-to-peer (P2P) protocols. Encryption is common in these applications and partially successful in overcoming these ISP controls, but even if all users and applications used strong encryption this would not succeed in overcoming decisions by ISPs simply to route known premium traffic to a 'faster lane', consigning all other traffic into a slower nonpriority lane (a policy explanation simplifying a complex engineering decision). $\mathrm{P} 2 \mathrm{P}$ is designed to make the most efficient use of congested networks, and its proponents claim that with sufficient deployment, P2P could largely overcome congestion problems.

Traffic management techniques affect not only high-speed, high-money content, but by extension all other content too. You can only build a high-speed lane on a motorway by creating inequality, and often those 'improvement works' slow down everyone currently using the roads. The Internet may be different in that regulators and users may tolerate much more discrimination in the interests of innovation. To make this decision on an informed basis, it is in the public interest to investigate transparently both net neutrality 'lite' (the slow lanes) and net neutrality 'heavy' (what rules allow higher speed content). For instance, in the 
absence of oversight, ISPs could use DPI to block some content altogether, if they decide it is not to the benefit of ISPs, copyright holders, parents or the government. ISP blocking is currently widespread in controlling spam email, and in some countries in blocking sexually graphic illegal images.

\section{Measuring Congestion and Internet Traffic Growth}

One of the main claims by ISPs wishing to traffic manage the Internet is that Internet traffic growth is unmanageable by traditional means of expansion of bandwidth and that therefore their practices are reasonable. In order to properly research this claim, regulators need access to ISP traffic measurement data. There are several possible means of accessing data at Internet Exchange points, but much data is private either because it is between two peers who do not use an exchange, or because it is carried by a CDN.

Odlyzko's traffic measurement in the Minnesota Internet Traffic Studies (MINTS 2009) project shows that, based on best available sources of Internet traffic growth is far from explosive, in fact global traffic continues to grow at $40-50 \%$ as it has most of the millenium, a much lower level than at its peak. It will never reach the levels of doubling every hundred days that convicted fraudster Bernie Ebbers claimed in the late $1990 \mathrm{~s}^{1}$. Odlyzko and Levinson (2007) refute many arguments for fine-scaled charging noting that:

Technology appears to be making fine-scale charging (as in tolls on roads that depend on time of day or even on current and anticipated levels of congestion) increasingly feasible. Standard economic theory supports such measures, and technology is being developed and deployed to implement them. But their spread is not very rapid, and prospects for the future are uncertain ... the case for fine-scale charging is not unambiguous, and in many cases may be inappropriate.

Yoo (2011: footnote 10) has criticized Odlyzko's methodology for failing to account for rapidly-growing off-net traffic such as Content Delivery Networks. However, Odlyzko's project (MINT 2010) flagged the $\mathrm{CDN}$ issue several years ago when requesting access to those networks ${ }^{2}$. Even if traffic is actually growing a full ten percentage points higher than available from MINTS sources, that places it in the historically manageable 50-60\% range, though ATLAS (Labovitz et al 2009) suggests the growth may be higher.

One must conclude that improving on MINTS data is a research necessity, yet no government regulator has produced any more reliable data and carriers' and CDNs' own data is subject to commercial confidentiality (for instance Google's proprietary CDN). In June 2009, Epitiro benchmarking tests showed UK broadband running at $0.9 \mathrm{Mbps}$ in evening peak time, a rate below that which would permit video streaming of the BBC iPlayer. The delays to the network also made it unreliable for video gaming or VOIP (ThinkBroadband 2009): "users received on average $24 \%$ of the maximum 'up to' headline speeds advertised.... During peak hours (6 pm to midnight) speeds dipped by approximately $20 \%$...Ping times, an important metric for online game playing came in at around $150 \mathrm{~ms}$ which is too high for acceptable gaming performance."

\subsection{The Special Case of Wireless or Mobile Net Neutrality?}

Mobile remains a poor substitute for the fixed Internet, and mobile smartphone users (the most advanced mobile users) in 2010 only downloaded an average of 79 Megabytes per month, according to Cisco Systems data. It is misleading to use headline percentage growth to suggest there is a major congestion issue - people are finally using the Internet on mobile networks via dongles and smartphones, so absolute usage is increasingly slowly compared to growth. Mobile data traffic was in 2010 a total of 237 Petabytes, which Cisco states is three times greater than the entire Internet in 2000. More relevant is that it is $1 \%$ of the Internet in 2010, a global total of 21 Exabytes. If mobile data grows twice as fast as the global Internet for the next decade years, it will amount to $11 \%$ of the entire Internet by 2020 . At that point, it will become more than a statistical insignificance in global terms. Mobile claims should be met with robust scepticism as mobile is such a minute part of the entire Internet traffic measured, and indeed a substantial part of

\footnotetext{
${ }^{1}$ Loose use of statistics appears endemic in the measurement of Internet traffic, with even recent academic papers claiming that MINT reports $100 \%$ annual growth! See Haßlinger et al (2011).

${ }^{2}$ MINTS (2007) Methodology, page last modified 30 August, at http://www.dtc.umn.edu/mints/methodology.html stating that "Sites that make traffic statistics publicly available are definitely not a representative sample of all those on the Internet. They tend to be Internet exchanges and academic and research network, with only a smattering of private companies or commercial service providers." Using Internet exchanges as proxies for overall measurement in 2007 meant that they MINTS results were likely higher than the overall Internet, though CDNs may have since grown faster.
} 
mobile 'traffic' is intended in future to be handed off to femtocells, WiFi cells, and other fixed wireless infrastructure, piggybacking on the relatively stable and mature fixed Internet that is expanding to meet capacity. By contrast, Japanese fixed ISPs announced a traffic cap of 30 Gigabytes upload per day ${ }^{3}$. Mobile is a trivial proportion of overall Internet traffic by volume, but commands massive premiums over fixed traffic for the service provided.

Cisco (2011) released a wireless data forecast, which included useful information that: [a] average smartphone use has increased from $35 \mathrm{MB}$ to $79 \mathrm{MB} /$ month, 0.93 Gigabytes a year.

[b] there is decreased bandwidth hogging (which means more people actually use their Gigabyte) with $10 \%$ of users accounting for $60 \%$ of total data: "mobile data traffic has evened out over the last year and now matches the 1:20 ratio that has been true of fixed networks for several years".

That does not account for national variations. In the US where LTE has been deployed and iPhone usage began (47\% of all new phones are smartphones according to Sprint), the average user on Sprint uses $325 \mathrm{MB}$ a month, and a consultant (Malik 2010) claims that the United States alone generated 1024 Petabytes of traffic in 2010 - which contrasts sharply with Cisco's much lower and more respected figure.

European regulators' group BEREC (2010: 11) has explained: "mobile network access may need the ability to limit the overall capacity consumption per user in certain circumstances (more than fixed network access with high bandwidth resources) and as this does not involve selective treatment of content it does not, in principle, raise network neutrality concerns." They explain that though mobile will always need greater traffic management than fixed ("traffic management for mobile accesses is more challenging"), symmetrical regulation must be maintained to ensure technological neutrality: "there are not enough arguments to support having a different approach on network neutrality in the fixed and mobile networks. And especially future-oriented approach for network neutrality should not include differentiation between different types of the networks." BEREC (2010: 3) concluded that mobile should be subject to the "net neutrality lite' provisions available under Directives 136/2009/EC and 140/2009/EC, listing some breaches of neutrality: "blocking of VoIP in mobile networks occurred in Austria, Croatia, Germany, Italy, the Netherlands, Portugal, Romania and Switzerland". The FCC's comment period on their Open Internet inquiry, specifically asked for answers to regulation of managed specialized services, and wireless net neutrality. The FCC announced in their (FCC 2010) Order that they were prepared not to enforce their proposed regulation on wireless services in the near future. This means that the faster growing and more competitive US market will be less regulated, whereas the more sluggish and less competitive European market will be.

\section{Law and Net Neutrality}

Although net neutrality was the subject of FCC regulatory discussions and merger conditions from 2003 (Frieden, 2010), its status was unsure in mid-2011 with no legislation passed by Congress, and FCC actions reserved to isolated examples of discrimination that were litigated (Comcast v. FCC, 2010). Net neutrality has been most effectively carried into legislation or regulation in Japan and the European Union, as well as Norway and Canada (where it is called ITMP: De Beer, 2009). The European institutions in late 2009 agreed to impose transparency and net neutrality 'lite' conditions on ISPs, in directives that had to be implemented in national law by May 2011. BEREC (2010) note that legal provisions in the Directives permit greater 'symmetric' regulation on all operators, not simply dominant actors, but ask for clarification on these measures: "Access Directive, Art 5(1) now explicitly mentions that NRAs are able to impose obligations "on undertakings that control access to end-users to make their services interoperable". Furthermore, the new wider scope for solving interoperability disputes may be used in future:

"revised article 20 of the Framework Directive now provides for the resolution of disputes between undertakings providing electronic communications networks or services and also between such undertakings and others that benefit from obligations of access and/or interconnection (with the definition of "access" also modified in Art 2 AD as previously stated). Dispute resolutions cannot be considered as straightforward tools for developing a regulatory

\footnotetext{
${ }^{3}$ That is 1200 times more than the average mobile user, and only refers to downloading with absolutely no upload limit. See http://bit.ly/i9IS93 (Google translation used)
} 
policy, but they do provide the option to address some specific (maybe urgent) situations. The potential outcome of disputes based on the transparency obligations can provide a "credible threat" for undertakings to behave in line with those obligations, since violation may trigger the imposition of minimum quality requirements on an undertaking, in line with Art 22(3) USD."

Therefore BEREC identifies the weapons at its disposal, further puncturing the widespread United States press claim that Europe has taken no action on net neutrality. The Wall Street Journal even declared that the "net neutrality debate in Europe is 'over'" (Rooney 2011) ${ }^{4}$. Though widely re-reported and perhaps wishful thinking, it is not correct. The European Commission is in 2011 consulting on the future of the Universal Service Obligation (EC, 2010) which may be extended to 2Mbps broadband (impacting member state law in 2012), which will mark a new 'line in the sand' in Europe for minimum service levels. That will also require commitments to offering that level of access to the open Internet, not a throttled, blocked, walled garden area.

At national level, EU member states have been slow to recognise net neutrality problems, despite strong anecdotal evidence arising. The chief executive of TalkTalk revealed at UK regulator Ofcom's 2006 conference that he was receiving death threats from online gamers upset that their connections were being throttled during evening peak hours (Dunstone, 2006). Yet despite this and other evidence, notably the throttling of BBC iPlayer video distribution by the incumbent British Telecom, Ofcom has confined itself to measuring ISP broadband performance, making it easier for consumers to switch to rival providers (Kiedrowski, 2007). The government itself has been inert, even erroneously reporting to the European Commission in its 15th Annual Implementation Report on telecoms liberalisation that no problems were occurring.

European Economic Area (not full EU) member, Norway, dealt with net neutrality earlier. A complaint first arose due to a dispute between an ISP, NextGenTel, and the Norwegian state broadcaster NRK in mid-2006 (Marsden, 2010a, pp. 172-173). NextGenTel limited the bandwidth available to the website of NRK, which the operator said was generating excessive traffic caused by its subscribers streaming free Internet TV provided by the broadcaster. NRK published a statement on its website stating that NextGenTel had considerably decreased the transfer capacity from its website to NextGenTel broadband customers. According to the broadcaster, the operator had asked for an additional payment for an increase in capacity. In its statement, NRK said that the matter was out of its control and that NextGenTel customers should contact the ISP directly - which many customers did, according to local reports. NextGenTel threatened to place a 1 Gigabit per second cap on traffic from NRK. The regulator in Norway persuaded the ISPs and cable companies to sign a co-regulatory pact on transparency and consumer rights in 2009. The Norwegian Code (2009) states:

- Internet users must be given complete and accurate information about the service they are buying, including capacity and quality.

- Users may send and receive content of their choice, use services and applications of their choice and connect any hardware and software that does not harm the network.

- The connection cannot be discriminated against based on application, service, content, sender or receiver.

\footnotetext{
${ }^{4}$ Rooney, Ben (2011) Net Neutrality Debate in Europe Is 'Over' February 28, at http://blogs.wsj.com/tech-europe/2011/02/28/netneutrality-debate-in-europe-is-over/?mod=google_news_blog, arguing based on textual analysis of Kroes' pronouncements but failing to note the recent reform of European telecoms law which BEREC describes above:

“At her confirmation hearing in January 2010 she said Internet providers, “shouldn't be allowed to limit the access to service or content out of commercial motivation, but only in cases of security issues and spamming." By April, speaking at the ARCEP Conference in Paris, her categorical had become a rhetorical: "Should Internet providers be allowed to prioritize one kind of internet usage over another? (for instance delaying peer-to-peer applications). And should they be able to charge for that?" Some seven months later speaking at a summit on "The Open Internet and Net Neutrality in Europe," her position had shifted even further. Blocking and "throttling" of sites and applications continues to a certain extent, she said: "This clearly creates a problem if consumers are not duly informed and do not have the possibility to easily switch to alternative providers...I say to those people who are currently cut off from Skype: vote with your feet and leave your mobile provider." A spokesman for Ms. Kroes said the commissioner's position now was that a competitive market should be able to deliver an Internet to which everyone has access: "She is confident that a competitive market should be able to deliver that, within the framework of the guarantees put in place by last year's Telecoms Package. At the same time, the development of the market, including any commercial arrangements, should be followed closely so that regulatory or other interventions can be initiated if necessary."
} 
Net neutrality is politically controversial in Canada, where a celebrated breach took place in 2005 (De Beer, 2009). The regulator announced an evidence-based inquiry into net neutrality held in 2009. It held open hearings, stating: 'The issue of Internet traffic management practices is increasingly a global issue that is being raised in other jurisdictions'. As a result, new principles of transparency and non-discrimination were declared; these await cases and regulatory decisions in which to add detail to the broad declarations.

In the United States, President Obama came into office in January 2009 committed to net neutrality regulation (Marsden, 2010a, p. 1). A Notice of Proposed Rule Making (NPRM) by the FCC under Democrat Chair Julius Genachowski extended a consultation on net neutrality over 2009-10, with over 27,000 submissions made to the NPRM. This process was finishing just as the Court of Appeal in April 2010 (Comcast v. FCC, 2010) judged that the FCC's regulatory actions in this area were not justified by its reasoning under the Communications Act 1996. Ammori (2010) claims the case presented three findings:

1. Would the carriers interfere with Internet content and applications? "Carriers would not only interfere, and with very popular technologies, they would lie about it, over and over, and then when caught, lie some more. And afterward, they'd keep lying, and keep blocking. If the FCC learned anything during that investigation, it is that Comcast was not a good faith actor."

2. Would the FCC punish bad actors? "[I]t turned out, to our surprise, the answer was yes."

3. Does the FCC have jurisdiction to protect consumers, preserve an open Internet? No.

The successful Comcast appeal meant that the FCC had to either reclaim Title II common carrier authority for ISPs under the 1996 Telecommunications Act, else ask Congress to re-legislate to grant it Title I authority, or try to assert its own Title I authority subject to legal challenge (Marsden 2010a). It adopted this last course in its Order of 23 December 2010 (FCC 2010), to be challenged before the courts in 201112. This stay of regulatory action may leave the FCC in suspended animation for much of 2011-12, and researchers must look elsewhere for net neutrality regulation (Marsden 2010b; Meisel, 2010). Donahue (2010: 7) concludes that 'to the extent the exercise yields guidance, its findings may contribute to public policy and Internet governance abroad'.

\subsection{Bandwidth caps}

Usage based billing (UBB), to use the Canadian expression, is not new in Internet policy, being the default in most countries prior to the introduction of broadband modems in the late 1990s. Only in countries with unmetered local calls, such as Canada and the United States, was Internet use 'all you can eat'. UBB became a headline issue in 2010 in both the United States and Canada, arguably because consumers in these countries had rarely been previously rationed in their Internet usage, whereas Europeans were rationed on a pay-per-minute basis throughout the 1990s, first sampling unmetered Internet only with the introduction of Flat Rate Internet Access Call Origination (FRIACO) in 2000, exactly as broadband was supplanting narrowband ('dial-up') access (Oftel 2000).

Different practices have been identified by Geist (2011):

- Most countries' ISPs give consumers the ability to select from among unlimited and capped services, the latter at lower prices.

- $\quad$ All plans are effectively unlimited plans but with different speeds once a data threshold is met, as with BT in the UK which "rate limits" subscribers that exceed their cap (typically 250GB/month) by reducing download speeds for the remainder of the month.

- $\quad$ Many Australian ISPs feature two separate data caps each month - one for peak time usage and a second for off-peak usage. The peak period may run for several hours (in the UK up to fourteen hours with Virgin Cable as of March 2011), off-peak period the remainder. A rate-limited service takes over if subscribers exceed either cap.

- $\quad$ Some ISPs distinguish between domestic and international data e.g. Vodafone Iceland offers a 10 GB capped plan but "all data downloaded domestically is unlimited without any extra cost" (note: international data will often require a transit arrangement that increases data transfer costs).

- The final approach identified is to distinguish between upstream and downstream traffic. Japanese ISPs with data caps limit their application to upstream traffic. 
Further research is clearly needed to identify the types of caps which reflect ISPs' costs, and those which are potentially market-stifling or anti-competitive.

Most UBB relates to maximum download capacity, and is assessed independently of the maximum download speeds which users can receive, the latter being the 'headline rates' that are generally used in broadband advertising to consumers. OECD (2008) shows that of 215 broadband packages sampled, almost half would result in users exceeding their monthly caps within three hours at advertised maximum speeds. OECD (2010) shows that while two countries (Japan, South Korea) have replaced almost half of their copper lines with fibre, the vast majority are still copper-based and therefore are using nineteenth century technology to try to deliver broadband services. The actual bandwidth caps used vary enormously across OECD countries, from only 250MB for the basic Australian product surveyed by OECD in 2008, to a 30Giga Bytes per day UPLOAD limit imposed by KDDI in Japan in January 2011 (equating to 3,000,000 times more than Australia's limit, this being only an upload limit). There is therefore wide variation in practices between countries.

The cost of fibre in the local loop is in itself no major constraint on capacity: it is the backhaul cost from the telephone exchange to the Internet that is the constraint here. Burstein (2011) has stated his belief that caps are designed to prevent 'over-the-top' (OTT) video to be delivered via broadband, competing with the triple-play offers of ISPs which want subscribers to pay for a telephone line, broadband service and cable or Internet delivered video programming. OTT video would compete with the last of these services, and degrading or capping the broadband service can protect the incumbent's video service. See further on this theme Crawford (2011). Comcast in the US created a 250GB cap in 2008 (Burstein 2008), which was considered more transparent than its previous usage of DPI and other techniques led by its subcontractor Sandvine to prevent Peer-to-Peer transfers. Burstein estimates the backhaul costs to ISPs as under $\$ 1 / \mathrm{month}$, whereas Ofcom (2006) five years ago estimated the costs of backhaul for BBC's iPlayer video catch-up service to UK ISPs as in the order of $£ 4-5 /$ month . Prices have clearly fallen rapidly with increases in transmission efficiency in that period (Moore's Law alone will have decreased prices by $75 \%$ over five years).

With the introduction of broadband cable in Canada, its regulator the Canadian Radio-television and Telecommunications Commission (CRTC) permitted UBB with monthly download caps on users. This was justified by the shared resource used by cable modem subscribers in the local loop. However, all broadband users share the backhaul capacity from the local loop to the Internet, capacity which must be bought wholesale from the incumbent in most cases. Therefore, incumbents can control the capacity available to competitive ISPs. The CRTC (2011) reiterated its permission for UBB, justified by reference to its responsibilities to ensure competition under Section 7 of the Telecommunications Act 1993. Geist may also illustrate the danger in believing the grass to be greener on the other side, a particular danger in Internet regulation where the path dependency and technological particularity of the policy arena tends to inexact comparisons - on which see Bauer (2010) for a recent reminder of the pitfalls in comparative research.

Countries which were bottom of the OECD tables for bandwidth provision in 2008, Australia and New Zealand have adopted the radical step of commissioning a national fibre local loop to replace their incumbent telephony monopoly. Public intervention is by no means a taboo in broadband investment, and the European Commission has repeatedly approved all non-urban public investment in fibre deployments proposed by Member States. Broadband is not an investment to be left wholly to the private sector, and investment incentives such as permitting UBB will not of themselves ensure national fibre to the premises.

\subsection{Transparency}

One of the several principles of network neutrality promulgated by both the FCC and European Commission is that only 'reasonable network management' be permitted, and that the end-user be informed of this reasonableness via clear information (Faulhaber 2010). Both the FCC in the US and the European Commission have relied on non-binding declarations to make clear their intention to regulate the 'reasonableness' of traffic management practices. In Canada, the CRTC has relied on inquiries to the dissatisfaction of advocates, while in Norway and Japan non-binding self-regulatory declarations have been thus far non-enforced. In the UK, Ofcom has tried to encourage industry self-regulation via transparency Codes of Conduct, which have been unconvincing as recalcitrant industry players have agreed to only minimal restrictions on their commercial freedom to impose arbitrary limits on consumers' behaviour. From May 2011, both European regulators and the European Commission will begin to attempt to define 'reasonable traffic management' 
for the purposes of the European law on Internet traffic. This is likely to produce more robust guidelines for both ISPs and consumers by 2012 (Sluijs 2010). By contrast, the FCC Open Internet order has been disapproved by the House of Representatives' challenged (thus far unsuccessfully) in court, and its order against the cable ISP Comcast is also being challenged. Research into the legal ramifications of FCC attempts to enforce any type of net neutrality rule may illustrate the difficulties in achieving traction for agency rules.

The European law was in 2009 amended to include the following:

'19. Transparency obligations on public communications network providers providing electronic communications services available to the public to ensure end-to-end connectivity, ...disclosure regarding any conditions limiting access to and/or use of services and applications where such conditions are allowed by Member States in conformity with Community law, and, where necessary and proportionate, access by national regulatory authorities to such information needed to verify the accuracy of such disclosure,

These obligations are to be implemented by May 2011, and details remain to be worked out.

The Canadian CRTC made rules in 2009, and its transparency requirements are:

- Is the network management technique designed to prevent a certain practice?

- Is it narrowly tailored?

- Does it cause as little harm as possible to the customer?

- Is there any less intrusive way to achieve the same result?

- The technique must be advertised 30 days in advance, and must be explained so that the average customer can understand: why will it be used, when will it occur, what type of traffic is subject and how will it affect the users internet experience including the effect on speed?

- Data gained from administering a network management practice must be destroyed as soon as it is not needed to preserve customer privacy.

There is little evidence of the enforcement of these CRTC principles (Geist 2011).

In Europe, little was done to define reasonableness and transparency by the European Commission prior to the implementation deadline, though Ofcom in the UK has carried out measurement of ISP practices in collaboration with SamKnows, a consultancy that has also worked with the FCC. SamKnows is measuring the following seventeen metrics over 2010-12: Latency (ICMP based); Packet loss (ICMP based); DNS query resolution time; DNS query failure rate; Web page loading time; Web page failure rate; VoIP call quality (MOS); VoIP call jitter, delay, packet loss; SMTP relaying speed; Web based download speed test (HTTP); Web based upload speed test (HTTP); Non web-based download speed test; Non web-based upload speed test; Single-stream download speed test; Multi-stream download speed test; Single-stream upload speed test; Multi-stream upload speed test ${ }^{6}$. It has worked with Ofcom since 2008, and the FCC since 2010 (with the latter it is conducting 11 test over a three year period). US FCC-SamKnows tests with project name TestMyISP are also supported by the Measurement Lab, notably the New America Foundation.

Transparency is a work in progress, and best regulatory information practices have yet to emerge - without such practices, any commitment to net neutrality is specious. Faulhaber (2010) has suggested four basic principles based on examination of other industries' information regulation: "disclose all information relevant to customer choice, 2) to which customers have easy access, 3) clearly and simply, and 4) in a way that is verifiable." He argues that Comcast would not have been reprimanded by the FCC had its traffic management been more transparent. We can suggest a fifth principle: information should be cross-compared by an accredited independent third party that is not reliant on broadband industry funding, such as a consumer protection agency. This could be carried out at arm's length via a self- or co-regulatory agreement, and it is to the type of arrangement that we now turn.

\subsection{Co- and self-regulation of net neutrality}

\footnotetext{
${ }^{5}$ Annex to Directive 2002/20/EC Authorisation Directive by Directive 2009/140/EC at OJ L337/68 18 December 2009.

${ }^{6}$ For more details and methodology, see http://www.samknows.com/broadband/ofcom_and_samknows for Ofcom and https://www.testmyisp.com/faq.html for the FCC tests.
} 
Net neutrality regulatory solutions under the 2009 European Directives had to be implemented by May 2011. They can be classified by the 'degree of self-regulation' involved, from basic informal communication through to formal regulation. The general trend is towards an expansion of scope of coregulation, often at the expense of statutory regulation. A wide variety of models of co-regulatory tools exist (EU, 2003), for those actions that require coordinated or joint implementation. Co-regulation provides backstop powers for governments to intervene where markets fail, and importantly also when constitutional rights such as freedom of expression are endangered. It is also designed to ensure that consumers and citizens have an independent voice in regulatory discussions. The term 'co-regulation' encompasses a range of different regulatory phenomena, which have in common that the regulatory regime is made up of a complex interaction with general legislation and a self-regulatory body that can be supplanted by state regulation should it be judged to have failed (Marsden et al, 2008; Tambini, Leonardi, Marsden, 2007). The varying interests of actors result in different incentives to cooperate or attempt unilateral actions at the various points of the value chain. Without self-regulation responsive to constitutional protection of freedom of expression at national levels, co- and self-regulatory measures cannot be self-sustaining. Examples are from a recent cross-sectoral EC study (Marsden 2011).

In the UK, Ofcom has continually attempted since 2008 to reach a self-regulatory solution, creating the unedifying spectacle of appearing to drag unwilling ISPs to the table to agree on what is at least formally 'self-regulation' though with the strongest of government pressure applied. By 2011, with the timetable for implementation of 2009/140/EC growing near, the government-funded Broadband Stakeholder Group (BSG) finally produced a Code of Conduct which remains extremely vague, and on which the UK government minister appeared to indicate that Berners Lee would play an oversight role to ensure compliance - this despite there being no formal adjudication mechanism (Vaizey, 2011). Whether such a ramshackle arrangement satisfies the European Commission, which is legally obliged to monitor implementation, remains to be seen in the course of 2012. It is likely to first ask the 27 Member States for details of their detailed implementations, before a further information request can be made which would be a prelude to a possible case for a preliminary ruling before the Court of Justice of the European Union (CJEU). Such a case would be unlikely to be heard before 2013 .

In the US, co-regulation is a novel concept, and the implementation of the technical means for measuring reasonable traffic management are to be tested in a self-regulatory forum, though with FCC blessing, the Broadband Industry Technical Advisory Group (BITAG), under Executive Director and FCC veteran Dale Hadfield. Its specific duties include that to offer 'safe harbor' opinions on traffic management practices' by parties making formal reference for an advisory technical opinion: "Specific TWG functions include: (i) identifying "best practices" by broadband providers and other entities; (ii) interpreting and applying "safe harbor" practices; (iii) otherwise providing technical guidance to industry and to the public; and/or (iv) issuing advisory opinions on the technical issues germane to the TWG's mission that may underlie disputes among discrete parties." (BITAG 2011: Section 7.1). BITAG has a broad multistakeholder constituency and is therefore far from simply an industry self-regulatory solution, but charges companies for testing of their solutions and is not currently mandated by law, therefore continuing to act as self- rather than co-regulatory forum ${ }^{7}$. As a Delaware-incorporated entity with published bylaws and an antitrust policy to formally exclude government activity, BITAG is a classic self-regulatory organisation in structure. US legal and policy scholars may wish to research the extent to which this offers advantages and costs in constitutional oversight and regulatory flexibility as compared with more administrative law supported bodies in Europe. Phil Weiser has proposed that a co-regulatory mechanism be supported (Weiser 2009).

\section{Other Public Policy Considerations in Net Neutrality}

Telecommunications regulators are aware that net neutrality is a more important issue than they are equipped or legally bound to explore, as the technologies at stake are technologies of censorship. BEREC (2010: 20) explains this clearly:

"Freedom of expression and citizens rights, as well as media pluralism and cultural diversity, are important values of the modern society, and they are worth being protected in this context especially since mass communication has become easier for all citizens thanks to the Internet. However intervention in respect of such considerations lies outside the competence of BEREC."

\footnotetext{
${ }^{77}$ For details see http://members.bitag.org/kwspub/BITAG_Membership/
} 
Putting a cash register on the Internet will permit much more granular knowledge of what an ISP's customers are downloading and uploading on the Internet. ISPs could filter out both annoying and illegal content. For instance, they could 'hear' criminal conversations, such as those by terrorist sympathisers, illegal pornographers, harassers, those planning robberies, libellous commentary and so on. They could also 'see' illegal downloading of copyrighted material. They would be obliged to cooperate with law enforcement or even copyright industries in these scenarios, and this could create even greater difficulties where that speech was legal in one country but illegal where it was received. Examples include English libel law, Australian pornography filtering, Chinese Falun Gong website blocking, Turkish YouTube bans, United States online gambling bans (Diebert et al., 2010). Net neutrality is therefore less unpopular with smaller ISPs that wish to avoid a legal liability morass, which Directive 2000/31/EC (E-Commerce Directive) and other national ISP non-liability 'safe harbor' [sic] laws are expressly designed to prevent.

Politicians in 2011 were reviewing the E-Commerce Directive (COM 2010, pp. 10-11), and passing local laws that favour, for instance, their copyright industries, such as the Digital Economy Act 2010 in the United Kingdom or the HADOPI law in France. In the discussions to amend the E-Communications Framework via Directives 2009/136/EC and 2009/140/EC, large well-resourced European incumbent ISPs saw the opportunity to make common cause with mobile operators (Wu 2007) and others, in an alliance to prevent transparency and permit filtering. The regulation of the Internet is erecting entry barriers with the connivance of the incumbent players, with potentially enormous consequences for free speech, for free competition and for individual expression. This may be the correct policy option for a safer Internet policy (to prevent exposing children to illegal and/or offensive content), though it signals an abrupt change from the open Internet (Zittrain 2008). It is therefore vital that regulators address the question of the proper 'lite' approach to net neutrality to prevent harm to the current Internet, as well as beginning to address the heavier questions of positive - or tiered - breaches of network neutrality.

Unsurprisingly, net neutrality regulation has been fiercely resisted by the ISPs, and its implementation has relied on a series of declarations and merger conditions prior to full implementation via regulations and legislation. Mergers afford regulators the opportunity to introduce such relatively minor adjustments as merger parties are eager to conclude the overall deal, and trade off the relatively minor inconvenience of controls on traffic management in the interests of successful approval. In the same way as consumers even with perfect information - may not view traffic management as the primary goal of their subscription to broadband (and are thus easy targets for restrictive conditions so long as industry standards prevent real choice between ISPs), so ISPs may make strategic choices to accept some limited traffic management conditions as a price of approval. The proposed 2011 merger of AT\&T Wireless and T-Mobile could also illustrate the propensity to enforce net neutrality via merger conditions, as could the merger of Level3 and Global Crossing, important Tier 1 backbone providers with extensive Content Delivery Networks.

Privacy inquiries can also impact on regulatory control of traffic management, with the UK government taken to the European Court by the European Commission for approving the both secret and invasive behavioural advertising practices of British Telecom and PHORM in 2006. The introduction of network neutrality rules into European law was under the rubric of consumer information safeguards and privacy regulation, not competition rules, and the US Congress is actively exploring privacy rules and controls on ISP behavioural advertising activities in 2011.

Finally, regulations passed in licensing can affect network neutrality at a fundamental level. Interoperability requirements can form a basis for action where an ISP blocks an application. Furthermore, wireless ISPs may be required to provide open access, as in the FCC auction of $700 \mathrm{MHz}$ Upper Block $\mathrm{C}$ frequencies in 2008 (Rosston and Topper 2010: 115-116), or in more general common carriage requirements traditionally imposed on public communications networks since before the dawn of modern communications, with railways and telegraphs (Railways Act 1844).

\section{The Future Development of Net Neutrality}

The future of the Internet is a non-trivial issue; in fact it is central to the future of productivity in most industries. It is an enabling technology, which means that the exchange of information on this open platform promises (and delivers) real efficiencies in the economy and society generally, as it helps collaboration and improvement (Carnoy et al., 1993). It is also socially enabling 'Web 2.0' or 'the participative web' (Schrage, 2000; Seely Brown and Duguid, 2000). That is, it has become a virtual playground, classroom, laboratory and chat room. Children, in particular, are now 'born digital' in many 
locales in developed society (Palfrey and Gasser 2008; Tapscott, 1999), and their access to the consumer Internet is an essential part of their development. Moreover, small businesses and solo home-based workers depend on this tool as a vital part of their participation in the economy. The promise of virtual worlds and massive online collaboration is to extend this impact even further by 2020 .

The 'Wealth of Networks' analysis of Benkler (2006) thinks of the Internet as a giant experiment, combining laboratory with user innovation and feedback, while Boyle (2008) describes a wider movement 'Enclosing the Commons of the Mind' and Post (2009) extends a comparison with Jeffersonian America. The open Internet is, it is constantly said, a commons. That is the basis for claims that it should be preserved and regulation induced to prevent any more enclosure of that commons, while at the same time ensuring that the commons is not ruined by free-riders - that there is no 'Tragedy of the Commons'. The open Internet is by no means the only or necessarily the most important place for public opinion to be formed, but it is the open public space that gives legitimacy to all these private or semi-private spaces.

The problems of development and the global Digital Divide are intimately connected to net neutrality. Internet connectivity is still very expensive for most developing countries, despite attempts to ensure local Internet peering points (exchanges) and new undersea cables, for instance serving East Africa. To flood the developing world's ISPs with video traffic, much of which came from major video production countries such as India, Nigeria and of course Hollywood, could place local ISPs in serious financial peril. Casualties in such undertakings include, for instance, countries blacklisted by major ISPs for producing large amounts of spam: Nigerian consumers have previously discovered that their email was blocked because the ISP was also used by spammers. The second development problem that net neutrality debate centres on is the wireless Internet. Most developing countries' citizens have much lower bandwidth than the west, and most of their connectivity is mobile: India is probably the poster child for a country with at least ten times more mobile than fixed phone subscribers. In the next several years, the developing world Internet user will test the limits of mobile networks, and capacity as well as price might determine the extent to which they can expect a rapidly developing or a Third World Internet experience. I flag up development issues because they are critical. Universal service is still a pipe dream for many in the developing world, and when that arrives, the definition it is given will determine the minimum threshold that ISPs have to achieve. As Mueller (2007: 7) states, net neutrality 'must also encompass a positive assertion of the broader social, economic and political value of universal and non-discriminatory access to Internet resources among those connected to the Internet'.

The types of non-net neutrality employed in Iran and China in June 2009 and West Asia/North Africa in winter 2010-11 were politically rather than economically motivated, that is, political censorship designed to prevent citizens' access to foreign discussion of the closely contested presidential elections, and the 20th anniversary of the Tiananmen Square massacre, respectively. Mueller (2007: 8) argues that the tendency of governments in both repressive and traditionally democratic regimes to impose liability on ISPs to censor content for a plethora of reasons argues for a policy of robust non-interference:

The flip side of a [network neutrality] policy that valorizes the right of Internet users to access each other without interference from intermediaries is the belief that network users wronged by other users must hold the wrongdoer responsible - not the intermediary network operator.

That is especially valuable in countries where there is much less discussion of how government deployment of ISPs as censors can endanger user privacy and freedom of expression. Mueller suggests that the net neutrality metaphor could be used to hold all filtering and censorship practices up to the light, as well as other areas of Internet regulation, such as domain name governance. Network neutrality has become an important policy issue discussed at the United Nations Internet Governance Forum (IGF). The IGF discussions of net neutrality has substantially increased (IGF, 2008, 2009).

We may expect to see more protest behaviour by 'netizens' who do not agree with net neutrality policies, especially where ISPs are seen to have failed to inform end-users fully about the implications of policy changes. Regulators and politicians are challenged publicly by such problems, particularly given the ubiquity of email, Twitter and social media protests against censorship, and there are two Pirate Party MEPs elected to the European Parliament (the Pirate Party is originally a Swedish political group dedicated to open and interchangeable digital information, notably a reduction in copyright enforcement). Research into social activism against corporate control of the Internet is a growing research field (Hart 2011). 


\section{Conclusions: Policy research into light-touch regulation}

The Internet's evolution is dynamic and complex. The availability and design of a suitable regulatory response must reflect this dynamism, and also the responsiveness of regulators and market players to each other. Therefore, national legislation should be future proof and avoid being overly prescriptive, to avoid a premature response to the emerging environment. The European legal basis for regulatory intervention in Directives 2009/136/EC and 2009/140/EC is an enabling framework to prevent competition abuses and prevent discrimination, under which national regulators need the skills and evidence base to investigate unjustified discrimination. Regulators expecting a 'smoking gun' to present itself should be advised against such a reactive approach. A more proactive approach to monitoring and researching non-neutral behaviours will make network operators much more cognisant of their duties and obligations. The pace of change in the relation between architecture and content on the Internet requires continuous improvement in the regulator's research and technological training. This is in part a reflection of the complexity of the issue set, including security and Internet peering issues, as well as more traditional telecoms and content issues. Regulators can monitor both commercial transactions and traffic shaping by ISPs to detect potentially abusive discrimination. No matter what theoretical powers may exist, their usage in practice and the issue of forensic gathering of evidence may ultimately be more important. An ex ante requirement to demonstrate internal network metrics to content provider customers and consumers may be a practical solution, via a regulatory or co-regulatory reporting requirement. Strong arguments remain for ensuring that ISPs inform consumers when they reach a monthly download limit or 'cap', Regulators should be wary of imposing costs on ISPs that are disproportionate. Very high entry barrier co-regulation and self-regulation can curb market entry. The need for greater research towards understanding the nature of congestion problems on the Internet and their effect on content and innovation is clear (Marsden et al, 2008).

The conclusion in a research handbook should emphasise the complexity of the problem than trying to claim a one-size-fits-all solution. I have categorised net neutrality into positive and negative (content discrimination) net neutrality indicating the latter as potentially harmful. Blocking content without informing customers appropriately is wrong: if it says 'Internet service', it should offer an open Internet (alongside walled gardens if that is expressly advertised as such). The issue of uncontrolled Internet flows versus engineered solutions is central to the question of a 'free' versus regulated Internet.

A consumer- and citizen-orientated intervention depends on passing regulations to prevent unregulated nontransparent controls exerted over traffic via DPI equipment, whether imposed by ISPs for financial advantage or by governments eager to use this new technology to filter, censor and enforce copyright against their citizens. Unravelling the previous ISP limited liability regime risks removing the efficiency of that approach in permitting the free flow of information for economic and social advantage. These conclusions support a light-touch regulatory regime involving reporting requirements and co-regulation with, as far as is possible, market-based solutions. Solutions may be international as well as local, and international coordination of best practice and knowledge will enable national regulators to keep up with the technology 'arms race'. 


\section{References}

Ammori, M. (2010) How I lost the big one bigtime, at http://ammori.org/2010/04/07/how-i-lost-the-bigone-bigtime/

Ayres, I. and J. Braithwaite, J. (1992) Responsive Regulation: Transcending the Deregulation Debate. Hartford, CT: Yale University Press.

Bauer, Johannes M. (2010) Learning from each other: promises and pitfalls of benchmarking in communications policy 12 Info 6 , pp.8-20

Benkler, Y. (1998a) 'Communications Infrastructure Regulation and the Distribution of Control over Content', Telecommunications Policy [online], 22(3), pp.183-196. Available from: http://www.benkler.org/PolTech.pdf [Accessed].

Benkler, Y. (1998b) 'Overcoming Agoraphobia: Building the Commons of the Digitally Networked Environment', Harvard Journal of Law and Technology [online], 11, pp. 287-400. Available from: http://www.law.nyu.edu/benklery/agoraphobia.pdf [Accessed].

Benkler, Y. (2006) The Wealth of Networks: How Social Production Transforms Markets and Freedom. New Haven, CT and London: Yale University Press.

BEREC (2010) 42 BEREC Response to the European Commission's consultation on the open Internet and net neutrality in Europe, at http://www.erg.eu.int/doc/berec/bor_10_42.pdf

Berners Lee, Tim (2006) Net Neutrality: This is serious, 2006-06-21 16:35, at http://dig.csail.mit.edu/breadcrumbs/node/144

BITAG (2011) By-laws of Broadband Industry Technical Advisory Group at http://members.bitag.org/kwspub/background_docs/BITAG_Bylaws.pdf

Boyle, J. (2008) The Public Domain: Enclosing the Commons of the Mind. New Haven, CT: Yale University Press.

Burstein, D. (2008) Comcast's Fair 250 Gig Bandwidth Cap, DSL Prime 21 October at http://www.dslprime.com/docsisreport/163-c/53-comcasts-fair-250-gig-bandwidth-cap

Burstein, D. (2011) Wireline Costs And Caps: A Few Facts, DSL Prime 6 March at http://www.dslprime.com/dslprime/42-d/4148-costs-and-caps

Carnoy, M., Castells, M., Cohen, S. S. and Cardoso, F. H. (1993) The New Global Economy in the Information Age; Reflections on Our Changing World. New York: Macmillan.

Cave, M., Collins, R., van Eijk, N., Larouche, P., Prosperetti, L., de Streel, A. et al. (2009) 'Statement by European Academics on the Inappropriateness of Imposing Increased Internet Regulation in the EU', 8 January 2009. Available from: http://papers.ssrn.com/sol3/papers.cfm?abstract_id=1329926 [Accessed]

Cherry, Barbara A. (2006) Misusing Network Neutrality to Eliminate Common Carriage Threatens Free Speech and the Postal System, 33 N. KY. L. REV. 483

Cherry, Barbara (2008) Back to the Future: How Transportation Deregulatory Policies Foreshadow Evolution of Communications Policies, The Information Society, p. 24

Cisco (2011) Visual Networking Index (VNI) Global Mobile Data Traffic Forecast at http://www.cisco.com/en/US/solutions/collateral/ns341/ns525/ns537/ns705/ns827/white_paper_c11520862.html

Clark David D. and Marjory S. Blumenthal (2011) The End-to-End Argument and Application Design: The Role of Trust, 63 Fed.Comm.L.J. 2 pp357-390

Clark, D. (1988) The Design Philosophy of the DARPA Internet Protocols, Computer Communications Review 18:4, August, pp. 106-114

COM (2002) 278 Better Regulation Action Plan 
COM (2010) 245, 'A Digital Agenda for Europe. European Commission, Brussels. Available from: http://ec.europa.eu/information_society/digital-agenda/documents/digital-agenda-communicationen.pdf [Accessed].

Comcast v. FCC (2010) No. 08-1291, delivered 6 April. Available from: http://pacer.cadc.uscourts.gov/common/opinions/201004/08-1291-1238302.pdf [Accessed].

Crawford, S. (2011) The Big Squeeze: The Looming Cable Monopoly, forthcoming

Crowcroft, J. (2011) The Affordance of Asymmetry or a Rendezvous with the Random? Communications and Convergence Review, in print [draft version]

CRTC (2011) Telecoms Decision 2011-44, Ottawa, 25 January 2011, Usage-based billing for Gateway Access Services and third-party Internet access services, File number: 8661-C12-201015975 at http://www.crtc.gc.ca/eng/archive/2011/2011-44.htm

De Beer, J. (2009) 'Net Neutrality in the Great White North (and its Impact on Canadian Culture)', Telecommunications Journal of Australia, 59 (2), pp. 24.1-24.19.

De Sola Pool, I. (1983) Technologies of Freedom. Cambridge MA: Belknap.

Deibert, R. J., Palfrey, J. G., Rohozinski, R. and Zittrain, J. (eds)(2010) Access Controlled: The Shaping of Power, Rights, and Rule in Cyberspace, Cambridge, MA: MIT Press.

Digital Economy Act (2010) Available from: http://www.opsi.gov.uk\%2Facts\%2Facts2010\%2Fukpga_20100024_en_1\&ei=LxwMTOCE56V4gaanIGbAQ\&usg=AFQjCNH1_aWgbfrLbgPyhm8lpQDOpaa_ww\&sig2=UOKxFp6oDeyxF exURnrn3A [Accessed].

Donahue, H. (2010) ‘The Network Neutrality Inquiry', info, 12 (2), pp. 3-8.

Dunstone, C. (2006) 'Presentation by Carphone Warehouse/TalkTalk CEO at the 2006 Ofcom conference. Available from: http://www.ofcom.org.uk/event/2006conference/presentations/session3 [Accessed].

Economides, N. and Tåg, J. (2007) 'Net Neutrality on the Internet: A Two-Sided Market Analysis'. Working Paper, NYU Center for Law and Economics, New York.

European Commission (EC) (2010) 'Consultation on the Future of the Universal Service Obligation'. Available from: http://ec.europa.eu/information_society/policy/ecomm/library/public_consult/univeuniv_service_20 10/index_en.htm [Accessed].

European Union (EU) (2003) 'Inter Institutional Agreement'. Available from: http://eurlex.europa.eu/LexUriServ/LexUriServ.do?uri= OJ:C:2003:321:0001:0005:EN:PDF [Accessed].

Faulhaber Gerald R. (2010) Transparency and Broadband Internet Service Providers, International Journal of Communication 4, pp.738-757

FCC (2005) Appropriate Framework for Broadband Access to the Internet Over Wireline Facilities et al., Policy Statement, 20 FCC Rcd 14986 (2005) (Internet Policy Statement);

FCC (2010) In the Matter of Preserving the Open Internet Broadband Industry Practices, GN Docket No. 09-191 WC Docket No. 07-52 REPORT AND ORDER Adopted: December 21, 2010

Frieden, R. (2010) Winning the Silicon Sweepstakes: Can the United States Compete in Global Telecommunications? Hartford, CT: Yale University Press.

Frieden, Rob (2010) Invoking and Avoiding the First Amendment: How Internet Service Providers Leverage Their Status as Both Content Creators and Neutral Conduits, 12 U. PA. J. CONST. L. p.1279;

Gaines, S. E. and Kimber, C. (2001) 'Redirecting Self-Regulation', Environmental Law, 13 (2), pp. $157-$ 184. 
Geist, Michael (2011a) Unpacking The Policy Issues Behind Bandwidth Caps \& Usage Based Billing, February 01, at http://www.michaelgeist.ca/content/view/5611/99999/

Geist, Michael (2011b) Canada's Usage Based Billing Controversy: How to Address the Wholesale and Retail Issues, March 2011,

http://www.michaelgeist.ca/component/option,com_docman/task,doc_download/gid,53/

Harris, Susan \& Elise Gerich, The NSFNET Backbone Service: Chronicling the End of an Era, 10 CONNEXIONS (April 1996), available at www.merit.edu/networkresearch/projecthistory/nsfnet/nsfnet_article.php

Hart Jeffrey A. (2011) The Net Neutrality Debate in the United States, Journal of Information Technology \& Politics, Issue 1, 2011, Page 1

Haßlinger, Gerhard, Giorgio Nunzi, Catalin Meirosu, Changpeng Fan, Frank-Uwe Andersen (2011) Traffic engineering supported by Inherent Network Management: analysis of resource efficiency and cost saving potential, International Journal of Network Management, at section 2, 25 JAN, DOI: 10.1002/nem.770

Internet Governance Forum (IGF) (2008) 'Network Neutrality: Examining the Issues and Implications for Development', Co-hosted Workshop, 4 December. Available from: http://techpolicyinstitute.org/events/show/77.html and http://www.intgovforum.org/cms/index.php/2008igf-hyderabad/event-reports/72-workshops/370-workshop-58-network-neutrality-examining-the-issuesand-implications-fordevelopment [Accessed].

Internet Governance Forum (IGF) (2009) 'Programme, Format and Schedule for the 2009 Meeting, Revision of 4 June 2009'. Available from: http://www.intgovforum.org/cms/2009/postings/ProgrammePaper.04.06.2009.rtf [Accessed].

Kiedrowski, T. (2007) 'Net Neutrality: Ofcom's View'. Available from: http://www.wwww.radioauthority.org.uk/media/speeches/2007/02/net_neutrality [Accessed].

Labovitz, C., S. Iekel-Johnson, D. McPherson J. Oberheide, F. Jahanian, M. Karir (2009) ATLAS Internet Observatory Annual Report, and their presentation to the North American Network Operators Group - $\quad$ an industry body - $\quad$ NANOG http://www.nanog.org/meetings/nanog47/presentations/Monday/Labovitz_ObserveReport_N47_Mo n.pdf

Lemley, M. A. and Lessig, L. (1999) 'Ex Parte Declaration of Professor Mark A. Lemley and Professor Lawrence Lessig in the Matter of: Application for Consent to the Transfer of Control of Licenses of Mediaone Group, Inc. to AT\&T Corp CS Docket No. 99-251 Before the Federal Communications Commission'.

Lessig, L. (1999a) Code and Other Laws of Cyberspace. New York: Basic Books.

Lessig, L. (1999b) 'The Limits in Open Code: Regulatory Standards and the Future of the Net', Berkeley Technology Law Journal, 14 (2), pp. 759-770.

Lessig, L. and Wu, T. (2003) 'Letter to the FCC Ex parte, 22 August 2003. Available from: www.timwu.org/wu_lessig_[Accessed].

Malik, O. (2010) Nov. 7: U.S. Mobile Data Traffic to Top 1 Exabyte, at http://gigaom.com/2010/11/07/in2010-us-mobile-data-traffic-to-top-1-exabyte/

Marsden, C. (2001) 'The Start of End-to-End? Internet Protocol Television', Intermedia, 29, pp. 4-8.

Marsden, C. (2010a) Net Neutrality: Towards a Co-regulatory Solution. London: Bloomsbury Academic.

Marsden, C. (2010b) 'Appeals Court Demolishes FCC Legal Argument for Ancillary Jurisdiction without Title I Argument in Comcast', 6 April. Available from: http://chrismarsden.blogspot.com/2010/04/appeals-court-demolishes-fcc-legal.html [Accessed]. 
Marsden draft “IDP 2011: Net Neutrality and other challenges for the future of the Internet", not to be cited

Marsden, C. (2011) Internet Co-regulation: European Law and Regulatory Legitimacy in Cyberspace, Cambridge: Cambridge University Press at http://www.cambridge.org/gb/knowledge/isbn/item6445008/?site_locale=en_GB

Marsden, C., Cave, J. et al. (2006) Assessing Indirect Impacts of the EC Proposals for Video Regulation, TR-414 for Ofcom. Santa Monica, CA: RAND.

Marsden, C., Simmons, S., Brown, I., Woods, L., Peake, A., Robinson, N. et al. (2008) 'Options for and Effectiveness of Internet Self- and Co-regulation Phase 2: Case Study Report' 15 January 2008. Prepared for European Commission DG Information Society \& Media. Available from: http://ssrn.com/abstract=1281374 [Accessed].

Mayer-Schonberger, V. (2008) Demystifying Lessig, Wisconsin Law Review, 4, pp. 713-746.

Meisel, J. P. (2010) 'Trinko and Mandated Access to the Internet', info, 12 (2), pp. 9-27.

MINTS (2007) Methodology, page last modified 30 August, at http://www.dtc.umn.edu/mints/methodology.html

MINTS (2009) "MINTS pages updated, many new reports, further slight slowdown in wireline traffic growth rate" November 17 at http://www.dtc.umn.edu/mints/news/news_22.html

Mueller Milton (1998) Universal Service: Competition, Interconnection, and Monopoly in the Making. AEI Press, Washington DC.

Mueller, M. (2007) 'Net Neutrality as Global Principle for Internet Governance'. Internet Governance Project Paper IGP07-003. Available from: http://internetgovernance.org/pdf/NetNeutralityGlobalPrinciple.pdf [Accessed].

Noam, E. M. (1994) 'Beyond Liberalization II: The Impending Doom of Common Carriage', Telecommunications Policy, 18 (6), pp. 435-452.

Noam, E. M. (2008) 'Beyond Net Neutrality: Enduser Sovereignty, Columbia University Draft Paper for 34th Telecoms Policy Research Conference, 14 August.

Norwegian Code (2009) 'Guidelines for Net Neutrality' Available from: http://www.npt.no/iKnowBase/Content/109604/Guidelines\%20for\%20network\%20neutrality.pdf [Accessed].

Odlyzko, Andrew and David Levinson (2007) Too expensive to meter: The influence of transaction costs in transportation and draft communication, at http://www.dtc.umn.edu/ odlyzko/doc/meteringexpensive.pdf

OECD (2008) OECD Broadband Portal, Table 5(m): Time to reach bit/data caps at advertised speeds (Sept. 2008), at http://www.oecd.org/dataoecd/11/15/39575302.xls

OECD (2010) OECD Broadband Portal, Table 11: Percentage of fibre connections in total broadband among countries reporting fibre subscribers, June 2010, at http://www.oecd.org/dataoecd/21/58/39574845.xls

Ofcom (2006) Market Impact Assessment: BBC new on-demand video proposals, at http://stakeholders.ofcom.org.uk/market-data-research/tv-research/bbc-mias/ondemand/bbc-ondemand/

Oftel (2000) Draft Direction under Condition 45 of the Public Telecommunications Licence granted to British Telecommunications plc of a dispute between BT and MCI Worldcom concerning the provision of a Flat Rate Internet Access Call Origination product (FRIACO), at http://www.ofcom.org.uk/static/archive/oftel/publications/internet/fria0400.htm, noting at point 3 that "BT cited concerns about network capacity and the principle of capacity charging".

Palfrey, J. and Gasser, U. (2008) Born Digital: Understanding the First Generation of Digital Natives. New York: Basic Books.

Post, D. (2009) In Search of Jefferson's Moose: Notes on the State of Cyberspace. New York: Oxford University Press. 
Marsden draft “IDP 2011: Net Neutrality and other challenges for the future of the Internet", not to be cited

Reidenberg, J. (2005) Technology and Internet Jurisdiction, University of Pennsylvania Law Review, 153, p. 1951.

Renda, A. (2008) 'I Own the Pipes, You Call the Tune: The Net Neutrality Debate and its (Ir)relevance for Europe'. CEPS Special Reports, Centre for European Policy Studies, Brussels.

Rooney, Ben (2011) Net Neutrality Debate in Europe Is 'Over' February 28, at http://blogs.wsj.com/techeurope/2011/02/28/net-neutrality-debate-in-europe-is-over/?mod=google_news_blog

Rosston, G.I. and Topper, M.D. (2010) An anti-trust analysis of the case for wireless net neutrality, Information Economics and Policy 22: 10, pp103-119.

Saltzer J.H., D. Reed and D. Clark (1981) End to End Arguments in System Design, Second International Conf. on Distributed Computing Systems, pp509-12

Schrage, M. (2000) 'The Debriefing: John Seely Brown', Wired, August, p. S.8.08.

Seely Brown J. and Duguid, P. (2000) The Social Life of Information. Cambridge, MA: Harvard Business School Press.

Sluijs Jasper P. (2010) Network Neutrality between False Positives and False Negatives: Introducing a European Approach to American Broadband Markets, Federal Communications Law Journal, Vol. 62, p. 77

Tambini, L. and Marsden, C. (2008) Codifying Cyberspace: Communications Self-Regulation in the Age of Internet Convergence. London: Routledge.

Tapscott, D. (1999) Growing Up Digital: The Rise of the Net Generation. New York: McGraw Hill.

Teubner, G. (1986) 'The Transformation of Law in the Welfare State', in G. Teubner (ed.), Dilemmas of Law in the Welfare State. Berlin: W. de Gruyter, pp.

Thinkbroadband (2009) Average mobile broadband speed clocks in at 0.9 meg, 10 June at http://www.thinkbroadband.com/news/p/2.html

Vaizey, Ed (2011) Hansard HC Deb, 5 April 2011, c259WH at http://www.publications.parliament.uk/pa/cm201011/cmhansrd/cm110405/halltext/110405h0002.htm\#1104 0557000591

Waclawsky, J. G. (2005) 'IMS 101: What You Need to Know Now'. Available from: http://www.oplan.org/documents/articles/IMS_need_to_know/fss_download/file [Accessed].

Weiser, P. (2009) The Future of Internet Regulation, 43 U.C. Davis L. Rev. pp.529-590

Werbach, Kevin (2005) The Federal Computer Commission, 84 N.C. L. REV. 1, 21

Werbach, Kevin (2010) Off the Hook, 95 CORNELL L. REV. p.535. Cherry, Barbara A. (2006) Misusing Network Neutrality to Eliminate Common Carriage Threatens Free Speech and the Postal System, 33 N. KY. L. REV. 483

Wu, T. (2003a) 'When Code Isn't Law', Virginia Law Review [online], 89, p. 679. Available from: http://papers.ssrn.com/sol3/papers.cfm?abstract_id=413201 [Accessed].

Wu, T. (2003b) 'Network Neutrality, Broadband Discrimination', Journal of Telecommunications and High Technology Law [online], 2, pp. 141-172. Available from: http://ssrn.com/abstract=388863 [Accessed].

Wu, T. (2007) 'Wireless Net Neutrality: Cellular Carterfone and Consumer Choice in Mobile Broadband'. New America Foundation Wireless Future Program Working Paper \#17, February.

Yoo, C. (2010) The Changing Patterns of Internet Usage, 63 Federal Communications Law. J. 1 pp.67-90 http://www.law.indiana.edu/fclj/pubs/v63/no1/2010-Dec.-Vol.63-05_Yoo.pdf

Zittrain, J. (2008) The Future of the Internet and How to Stop It. New Haven, CT: Yale University Press. 